Check for updates

Cite this: RSC Adv., 2017, 7, 20716

Received 26th December 2016 Accepted 27th March 2017

DOI: $10.1039 / c 6 r a 28687 a$

rsc.li/rsc-advances

\title{
Biodegradation of aliphatic and aromatic hydrocarbons using the filamentous fungus Penicillium sp. CHY-2 and characterization of its manganese peroxidase activity
}

\author{
Muthusamy Govarthanan, ${ }^{a}$ Soichiro Fuzisawa, ${ }^{b}$ Toshiki Hosogai ${ }^{a}$ \\ and Young-Cheol Chang (D) *ab
}

\begin{abstract}
The aim of this work was to study the potential of the non-lignolytic filamentous fungus Penicillium sp. CHY-2, isolated from Antarctic soil, for the biodegradation of eight different aliphatic and aromatic hydrocarbons such as octane, decane, dodecane, ethylbenzene, butylbenzene, naphthalene, acenaphthene, and benzo[a]pyrene. Among all the compounds, CHY-2 showed the highest level of degradation for decane $(49.0 \%$ ), followed by butylbenzene $(42.0 \%)$ and dodecane $(33.0 \%)$, and lower levels of degradation for naphthalene (15.0\%), acenaphthene (10.0\%), octane (8.0\%), ethylbenzene $(4.0 \%)$, and benzo[a]pyrene $(2.0 \%)$ at $20{ }^{\circ} \mathrm{C}$. The addition of carbon sources such as glucose $\left(5 \mathrm{~g} \mathrm{~L}^{-1}\right)$ and Tween-80 $\left(5 \mathrm{~g} \mathrm{~L}^{-1}\right)$ enhanced decane degradation by about 1.8 -fold and 1.61 -fold respectively at $20^{\circ} \mathrm{C}$. The metabolites produced during the degradation of decane were identified by gas chromatographymass spectrometry (GC-MS). Furthermore, the enzyme manganese peroxidase (MnP) from $\mathrm{CHY}-2$ was purified. MnP was found to consist of monomers with a molecular mass of $36 \mathrm{kDa}$. The purified MnP had an optimum pH of 5.0 and temperature of $30{ }^{\circ} \mathrm{C}$. The $K_{\mathrm{m}}$ and $V_{\max }$ values of $\mathrm{MnP}$ towards $\mathrm{Mn}^{2+}$ were $1.31 \mu \mathrm{M}$ and $185.19 \mu \mathrm{M} \mathrm{min}{ }^{-1}$ respectively. These results indicated that the strain $\mathrm{CHY}-2$ can be used for the degradation of hydrocarbons and could have promising applications in treatment of hydrocarbon contaminated sites.
\end{abstract}

\section{Introduction}

Hydrocarbons are one of the most common pollutants that are accumulated in the soil environment due to a variety of anthropogenic activities, and they potentially cause harmful effects on human health. ${ }^{1}$ The hydrophobic and tenacious nature of polycyclic aromatic hydrocarbons (PAHs) causes them to alter the biological and physicochemical properties of soil, such as the microbial population, soil enzyme activities, water holding capacity, and soil organic matter. ${ }^{2,3}$ Due to their negative effects on the environment and tendency to migrate into water bodies, there is an urgent desire to be able to remove PAHs from soil. ${ }^{4}$ Physico-chemical methods for the removal of PAHs are highly efficient but they change the soil structure, reduce the soil microbial population and lead to the depletion of nutrients that are essential for plant vegetation. ${ }^{5,6}$

\footnotetext{
${ }^{a}$ Department of Applied Sciences, College of Environmental Technology, Muroran Institute of Technology, 27-1 Mizumoto, Muroran, Hokkaido 050-8585, Japan. E-mail: ychang@mmm.muroran-it.ac.jp; Tel: +81-143-46-5757

${ }^{b}$ Course of Chemical and Biological Engineering, Division of Sustainable and Environmental Engineering, College of Environmental Technology, Muroran Institute of Technology, 27-1 Mizumoto, Muroran, Hokkaido 050-8585, Japan
}

Biodegradation is a biological process that utilizes natural microbial populations for the rapid elimination of PAHs from soil. ${ }^{7}$ The biodegradation of PAHs by microorganisms has been demonstrated as an efficient alternative to remove PAHs from contaminated soil. ${ }^{8}$ Several studies have been reported about PAH degradation using microorganisms. ${ }^{9-11}$ Among other microorganisms, fungi have certain advantages over bacteria with respect to biodegradation due to their resistance to PAHs. ${ }^{12}$

Filamentous fungi Penicillium sp. have received much attention as potential candidates for the degradation of a wide range of PAHs. ${ }^{13}$ The rapid growth rate, ability to grow under different environmental conditions, and ability to utilize a wide range of substrates as carbon and nitrogen sources enhanced the application of Penicillium sp. in biodegradation studies. ${ }^{14}$ Furthermore, numerous studies have reported the potential of white rot fungi for the biodegradation of PAHs and their extracellular manganese peroxidase activity. ${ }^{15,16}$ To date, most of the studies have reported about Penicillium sp. isolated from contaminated soil and water, while there is very little information available about Penicillium sp. isolated from Antarctic soil, ${ }^{17}$ a low temperature region of the Earth's last pristine wilderness. The environmental characteristics of Antarctica allow the fungus to thrive under low temperature conditions 
with diverse biodegradation potential. However, there are no reports about the degradation of PAHs by filamentous fungi Penicillium sp., under low temperature conditions.

Our previous study reported the biodegradation of alkylphenols by Penicillium sp. CHY-2 isolated from Antarctic soil. ${ }^{18}$ Consequently, the present work demonstrates the ability of Penicillium sp. CHY-2 to degrade hydrocarbons and PAHs under low temperature conditions and suggests that Penicillium sp. CHY-2 may be a useful tool for the biodegradation of PAHs in contaminated environments under low temperature conditions. In addition, the degradation ability of Penicillium sp. CHY-2 towards 8 different toxic hydrocarbons, octane, decane, dodecane, ethylbenzene, butylbenzene, naphthalene, acenaphthene, and benzo $[a]$ pyrene, was evaluated. The influence of different temperatures and $\mathrm{pH}$ levels on the biodegradation of PAHs by Penicillium sp. CHY-2 was also evaluated. Furthermore, the purification and characterization of MnP produced by Penicillium sp. CHY-2 were performed, and the PAH degradation potential of the purified MnP was evaluated under different temperature and $\mathrm{pH}$ conditions. In this study, the CHY-2 strain exhibited a great capability to degrade various hydrocarbons including decane under low and medium temperature conditions. In addition, MnP enzyme activities were observed during fungal growth on these compounds. These results suggest that the fungus CHY-2 has the ability to degrade aromatic and aliphatic hydrocarbons present in contaminated soils.

\section{Materials and methods}

\section{Strain and culture conditions}

Penicillium sp. CHY-2 (accession no: AB980801) was characterized in our previous study. ${ }^{18}$ Stock cultures of CHY-2 were maintained in potato dextrose agar (PDA) medium at $4{ }^{\circ} \mathrm{C}$. Penicillium sp. CHY-2 was first grown in $100 \mathrm{~mL}$ of potato dextrose broth in a $250 \mathrm{~mL}$ Erlenmeyer flask at $28^{\circ} \mathrm{C}$ for 5 days with a shaking speed of $200 \mathrm{rpm}$.

\section{Chemicals}

Octane, decane, dodecane, ethylbenzene, butylbenzene, naphthalene, acenaphthene, and benzo[a]pyrene were purchased from Tokyo chemicals (Tokyo, Japan) at a $97 \%$ purity level or higher. All chemicals used in this study were of analytical grade.

\section{Biodegradation of different hydrocarbons and PAHs by Penicillium sp. CHY-2}

Biodegradation experiments were performed in $100 \mathrm{~mL}$ serum bottles containing $50 \mathrm{~mL}$ of mineral glucose (MG) liquid medium. The MG medium contains the following composition: $1 \mathrm{~g} \mathrm{~L}^{-1} \mathrm{~K}_{2} \mathrm{HPO}_{4} ; 0.05 \mathrm{~g} \mathrm{~L}^{-1} \mathrm{NaCl} ; 0.2 \mathrm{~g} \mathrm{~L}^{-1} \mathrm{MgSO}_{4} \cdot 7 \mathrm{H}_{2} \mathrm{O} ; 0.05 \mathrm{~g}$ $\mathrm{L}^{-1} \mathrm{CaCl}_{2} ; 0.0083 \mathrm{~g} \mathrm{~L}^{-1} \mathrm{FeCl}_{3} \cdot 6 \mathrm{H}_{2} \mathrm{O} ; 0.014 \mathrm{~g} \mathrm{~L}^{-1} \mathrm{MnCl}_{2} \cdot 4 \mathrm{H}_{2} \mathrm{O}$; $0.017 \mathrm{~g} \mathrm{~L}^{-1} \mathrm{NaMoO}_{4} \cdot 2 \mathrm{H}_{2} \mathrm{O} ; 0.001 \mathrm{~g} \mathrm{~L}^{-1} \mathrm{ZnCl}_{2}$; and $5 \mathrm{~g} \mathrm{~L}^{-1}$ glucose. The medium pH was adjusted to 6 with $1 \mathrm{~N} \mathrm{HCl}$ and sterilized in an autoclave for $20 \mathrm{~min}$ at $121{ }^{\circ} \mathrm{C}$. Five disks $(10$ $\mathrm{mm}$ diameter) obtained with a cork borer from actively growing fungi on agar were placed into each bottle. The inoculated bottles were pre-cultivated for several days to obtain similar radial growths and minimize growth variation. Various toxic hydrocarbons and PAHs (at a final concentration of $100 \mathrm{mg}$ $\mathrm{L}^{-1}$ ), such as octane, decane, dodecane, ethylbenzene, butylbenzene, naphthalene, acenaphthene, and benzo[a]pyrene, were injected into separate bottles, and the bottles were incubated in the dark with an agitation speed of $110 \mathrm{rpm}$ under aerobic conditions. Hydrocarbons and PAHs in the liquid medium were extracted and measured by GC. The samples were shaken with equal volumes of hexane for $3 \mathrm{~min}$ and centrifuged at $8000 \mathrm{~g}$ for $10 \mathrm{~min}$. The organic layer was then extracted and analysed directly by GC-FID (flame ionization detection). The GC-MS analysis was conducted on a Shimadzu GC-MS system (GC-2014) with a DB-5MS capillary column (J \& W scientific). All samples were performed in triplicate and the results were expressed as mean values and standard deviations.

\section{Optimization studies for decane degradation}

The influence of temperature and $\mathrm{pH}$ on the decane degradation capacity of the CHY-2 strain was investigated under aerobic conditions. Batch experiments were conducted in $100 \mathrm{~mL}$ serum bottles containing $50 \mathrm{~mL}$ of the MG medium with different initial $\mathrm{pH}$ conditions (pH 5-9). Three disks $(10 \mathrm{~mm}$ diameter) of actively growing fungi on agar were placed into each serum bottle containing the MG liquid medium. $100 \mathrm{mg}$ $\mathrm{L}^{-1}$ decane was added to each bottle and the bottles were incubated for up to 28 days at different temperatures $(4,10$, and $20^{\circ} \mathrm{C}$ ) with an agitation speed of $110 \mathrm{rpm}$. Control experiments were performed without inoculation of the culture.

\section{Effect of glucose}

A monohyphal culture of CHY-2 was obtained by single spore isolation. The culture was maintained on $2 \%$ MG agar plates. Three different concentrations of glucose $\left(1,5\right.$, and $\left.10 \mathrm{~g} \mathrm{~L}^{-1}\right)$ were used. Uniform circular agar blocks containing a CHY-2 mycelial mat were cut from the 10 day old culture plate and transferred in to a sterilized $25 \mathrm{~mL}$ basal medium with $100 \mathrm{mg}$ $\mathrm{L}^{-1}$ decane. The inoculated bottles were incubated at 4 and $20{ }^{\circ} \mathrm{C}$ in a shaking incubator at $110 \mathrm{rpm}$. After 10 days of incubation, the cultures were spread on Petri plates containing different concentrations of glucose $\left(1,5\right.$, and $\left.10 \mathrm{~g} \mathrm{~L}^{-1}\right)$.

\section{Effect of Tween 80}

Batch experiments were carried out in $50 \mathrm{~mL}$ serum bottles containing $20 \mathrm{~mL}$ MG medium with and without Tween 80 addition. Four different concentrations of Tween $80(1,2.5,5$, and $10 \mathrm{~g} \mathrm{~L}^{-1}$ ) were used. Briefly, three disks (10 $\mathrm{mm}$ diameter) of actively growing CHY-2 were placed into each serum bottle containing the liquid medium. $100 \mathrm{mg} \mathrm{L}^{-1}$ decane was added to each bottle and the bottles were incubated for 28 days at 4 and $20^{\circ} \mathrm{C}$ with an agitation speed of $110 \mathrm{rpm}$. The effect of Tween 80 on decane degradation was observed according to Chang et al. ${ }^{18}$

\section{Analysis of decane metabolites by GC-MS}

The metabolites produced during decane degradation were determined by GC-MS. The samples were shaken with equal 
volumes of hexane for $3 \mathrm{~min}$ and centrifuged at $8000 \mathrm{~g}$ for 10 min. The organic layer was then extracted and analyzed directly by GC-MS. Prior to GC-MS analysis the extract was dried under a nitrogen flow and derived by trimethylsilylation (TMS) using an $\quad \mathrm{N}, \mathrm{O}$-bis(trimethylsilyl)trifluoroacetamide (BSTFA)/ acetonitrile solution at $60{ }^{\circ} \mathrm{C}$ for $1 \mathrm{~h}$. The GC-MS analysis was conducted on a Shimadzu GC-MS system (GCMS-QP2010) with an Rxi-5ms capillary column (30 m, $0.25 \mathrm{~mm} \mathrm{Id,} 1.00 \mathrm{~mm}$ df; Restek, PA, USA).

\section{Enzyme assay}

The activity of MnP from the culture filtrates was measured according to the method described by Wariishi et al. ${ }^{19}$ In brief, the reaction mixture $(1.0 \mathrm{~mL})$ contained $50 \mathrm{mM}$ malonic acid disodium salt monohydrate ( $\mathrm{pH} 4.5), 1.0 \mathrm{mM}$ manganese(II) sulfate, $0.1 \mathrm{mM}$ hydrogen peroxide $\left(\mathrm{H}_{2} \mathrm{O}_{2}\right)$ and the enzyme solution. The reaction was monitored for the formation of $\mathrm{Mn}^{3+}$ malonate complexes at $270 \mathrm{~nm}$. One unit (U) of MnP activity was defined as the amount of enzyme required to produce $1 \mathrm{M} \mathrm{Mn}^{3+}$ from the oxidation of $\mathrm{Mn}^{2+}$ per minute.

\section{Enzyme purification}

A four day old culture of Penicillium sp. CHY-2 was centrifuged for $10 \mathrm{~min}$ at $13000 \mathrm{~g}$. The supernatant was filtered through a $0.45 \mu \mathrm{m}$ filter (Advantec, Dismic-25AS, Bedford, USA). The filtrate served as the crude enzyme and it was subjected to various purification steps.

\section{Ion-exchange chromatography}

The first purification step involved a High Q cartridge (BioRAD, USA) column ( $5 \mathrm{~mL}, 40 \mathrm{~mm} \times 12.6 \mathrm{~mm}$ inner diameter $)$, which had been equilibrated with $50 \mathrm{mM}$ Tris-HCl buffer at $\mathrm{pH}$ 8.0. The flow rate was maintained at $0.5 \mathrm{~mL} \mathrm{~min}^{-1}$, and a total of 60 $1.0 \mathrm{~mL}$ fractions were collected. The protein concentration was determined for each fraction from the absorbance at $595 \mathrm{~nm}$ using the Bradford method. The MnP activity was then estimated as mentioned above for each fraction at $270 \mathrm{~nm}$. The fractions with high activity were collected and pooled. ${ }^{20}$

\section{Gel filtration}

The High Q cartridge fraction containing the MnP enzyme was concentrated to $1.0 \mathrm{~mL}$ by ultra-filtration using a $10000 \mathrm{Da}$ cutoff membrane at $4{ }^{\circ} \mathrm{C}$. The enzyme solution was then loaded onto a HiPrep 16/60 Sephacryl S-300 (GE Healthcare Sweden) column $(120 \mathrm{~mL})$ which was pre-equilibrated with $50 \mathrm{mM}$ PB $(\mathrm{pH}$ 7.2) and eluted with the same buffer. Fractions of $1.0 \mathrm{~mL}$ each were collected. All the fractions with high A270 and high MnP activity were pooled. The pooled samples were concentrated by ultra-filtration using a 10000 Da cut-off membrane at $4{ }^{\circ} \mathrm{C}$, and used for characterization. ${ }^{21}$

\section{SDS-PAGE}

The molecular mass of the purified enzyme was determined by sodium dodecyl sulfate-polyacrylamide gel electrophoresis
(SDS-PAGE). ${ }^{22}$ SDS-PAGE was run on a $12.5 \%$ polyacrylamide gel.

\section{Effect of $\mathrm{pH}$ and temperature on the activity of MnP}

The effect of $\mathrm{pH}$ on the $\mathrm{MnP}$ activity was studied at different $\mathrm{pH}$ values (3-7). In brief, the MnP was pre-incubated in $50 \mathrm{mM}$ malonic acid buffer ( $\mathrm{pH} 2.0-5.5)$ and $50 \mathrm{mM}$ potassium phosphate buffer ( $\mathrm{pH}$ 6.0-7.0) of different $\mathrm{pH}$ values in the range of 3-8 for $24 \mathrm{~h}$ at $30{ }^{\circ} \mathrm{C}$. After incubation, the residual enzyme activity was determined under standard assay conditions. Similarly, the effect of temperature on the MnP activity also determined at different temperatures between 4 and $40{ }^{\circ} \mathrm{C}$. Untreated enzyme was used as a control.

\section{Kinetic analysis of MnP}

The kinetic parameters of MnP toward $\mathrm{Mn}^{2+}$ were determined according to Zeng et al. $^{23}$ The rate of oxidation was determined by spectrophotometry using the reported molar extinction coefficient $(\varepsilon)$ values at the maximal absorption wavelengths. The reaction was conducted in $50 \mathrm{mM}$ malonic acid buffer and $\mathrm{MnP}$ (pH 5.5). The $K_{\mathrm{m}}$ and $V_{\max }$ values for the purified MnP from Penicillium sp. CHY-2 were calculated using the LineweaverBurk transformation of the Michaelis-Menten equation. ${ }^{24}$

\section{Decane degradation by MnP}

The decane degradation ability of purified $\mathrm{MnP}$ was determined according to Zeng et al. ${ }^{23}$ with minor modifications. Briefly, the purified MnP was incubated with decane for $48 \mathrm{~h}$ under the optimum $\mathrm{pH}(\mathrm{pH} 5.5)$ and temperature $\left(30^{\circ} \mathrm{C}\right)$. After the desired incubation period, the degradation rate was assayed using GCMS. Control experiments were performed without the inoculation of MnP.

\section{Statistical analysis}

All the results presented in this study were mean values of three replicates of experiments, and standard deviations were used to analyse the data. Statistical analysis was performed using Microsoft Excel 2013.

\section{Results and discussion}

\section{Biodegradation of 8 different hydrocarbons and PAHs by Penicillium sp. CHY-2}

The genus Penicillium is a group of fungi that exhibits a wide range of metabolic activities, including the degradation of various toxic compounds. ${ }^{18}$ Penicillium sp. has been demonstrated to as a potential fungus for the bioremediation of a wide range of hydrocarbons and PAHs. ${ }^{25}$ Singh $^{26}$ reported that Penicillium sp. is capable of using hydrocarbons as carbon and energy sources. Therefore, in the present study, Penicillium sp. CHY-2 was selected for the degradation of different hydrocarbons and PAHs. Biodegradation of the eight different hydrocarbons and PAHs at two different concentrations (100 and $500 \mathrm{mg} \mathrm{L}{ }^{-1}$ ) was investigated using the CHY-2 strain at $20{ }^{\circ} \mathrm{C}$ (Fig. 1). At $100 \mathrm{mg} \mathrm{L}^{-1}$ concentration, among all the compounds 


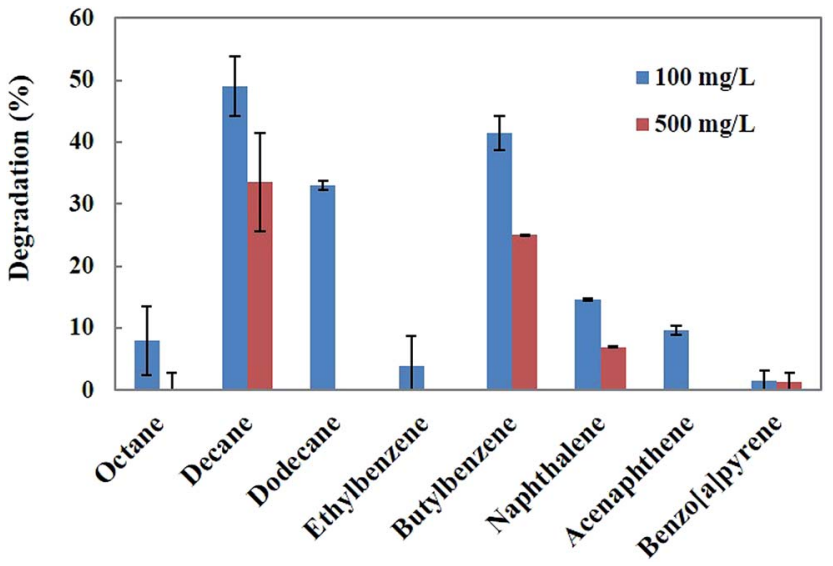

Fig. 1 Biodegradation of different hydrocarbons and PAHs by Penicillium sp. CHY-2.

studied, CHY-2 showed the highest levels of degradation for decane $(49.0 \%)$, followed by butylbenzene $(42.0 \%)$ and dodecane $(33.0 \%)$, and lower levels of degradation for naphthalene $(15.0 \%)$, acenaphthene $(10.0 \%)$, octane $(8.0 \%)$, ethylbenzene $(4.0 \%)$, and benzo[ $[a]$ pyrene $(2.0 \%)$. At $500 \mathrm{mg} \mathrm{L}^{-1}$ concentration, among all the compounds studied, CHY-2 showed the highest levels of degradation for decane $(34.0 \%)$ followed by butylbenzene $(25.0 \%)$, and lower levels of degradation for naphthalene $(7.0 \%)$ and benzo $[a]$ pyrene $(1.0 \%)$. However, other compounds such as octane, dodecane, ethylbenzene, and acenaphthene were not degraded by the strain. The rate of degradation was measured on day 28 at $20^{\circ} \mathrm{C}$. Apart from the white rot fungi, the filamentous Penicillium sp. also has the capacity to degrade a wide variety of organo-pollutants, including PAHs, phenolic compounds and heavy metals. ${ }^{25}$ Boonchan et al. ${ }^{27}$ reported that Penicillium janthinellum can oxidize PAHs into hydrophilic or detoxified products. Launen $e t a l .{ }^{28}$ reported that filamentous Penicillium janthinellum was capable of utilizing pyrene as a sole carbon and energy source. Degradation experiments showed that Penicillium janthinellum could oxidize or detoxify PAHs, and the mineralization of these compounds was not detected. In this study, the CHY-2 strain could effectively degrade hydrocarbons and PAHs. A significant increment of the

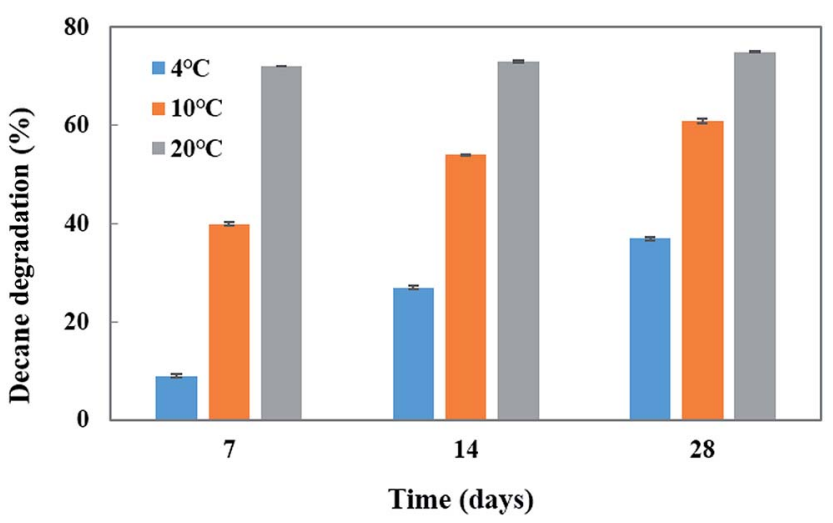

Fig. 2 Effect of temperature on decane degradation using $\mathrm{CHY}-2$.

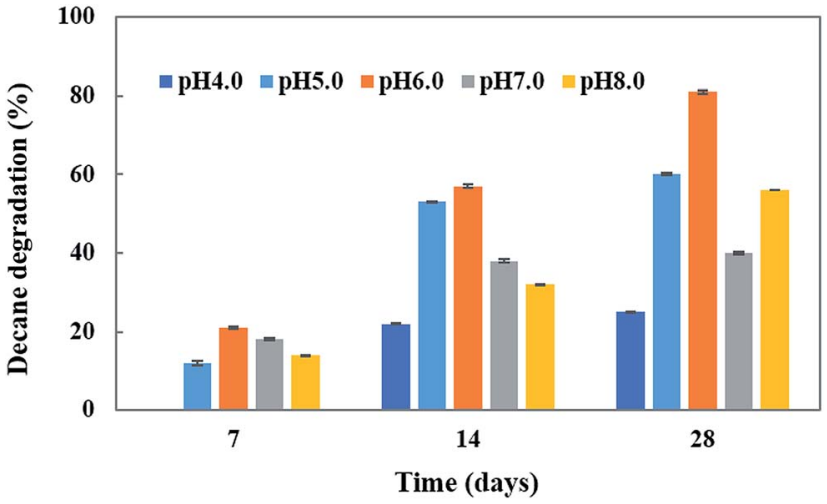

Fig. 3 Effect of $\mathrm{pH}$ on decane degradation using $\mathrm{CHY}-2$.

degradation rate was obtained at the concentration of $100 \mathrm{mg}$ $\mathrm{L}^{-1}$. Among the eight different hydrocarbons and PAHs, decane showed the highest percentage of degradation at both 100 and $500 \mathrm{mg} \mathrm{L}^{-1}$ concentrations. Therefore further studies were carried out on the degradation of decane using the CHY-2 strain.

\section{Optimization of decane degradation using CHY-2}

To investigate the effect of temperature and $\mathrm{pH}$ on decane (at $100 \mathrm{mg} \mathrm{L}^{-1}$ concentration) degradation by Penicillium sp. CHY2 , batch experiments were carried out at different temperatures $\left(4,10\right.$, and $\left.20^{\circ} \mathrm{C}\right)$ and different $\mathrm{pH}$ conditions (5-9) in a MG liquid medium. The CHY-2 strain grown at $20{ }^{\circ} \mathrm{C}$ for 28 days showed the highest percentage of decane removal ( $75 \%)$, followed by that for 14 days (73\%) and 7 days $(72 \%)$ of incubation time (Fig. 2). However, moderate removal of decane was observed at $10{ }^{\circ} \mathrm{C}$ at 28 days (61\%), 14 days (54\%), and 7 days (40\%). An interesting phenomenon was observed in this study, as the CHY-2 strain was able to degrade the decane even at $4{ }^{\circ} \mathrm{C}$. At 28 days $37 \%$ of decane degradation was observed followed by $27 \%$ at 14 days, and $9 \%$ at 7 days at a temperature of $4{ }^{\circ} \mathrm{C}$.

$\mathrm{pH}$ is an important abiotic factor which affects the microbial metabolism. Consequently, its effect on decane degradation was studied. The initial $\mathrm{pH}$ significantly influenced the growth and degradation rate of the $\mathrm{CHY}-2$ strain under acidic

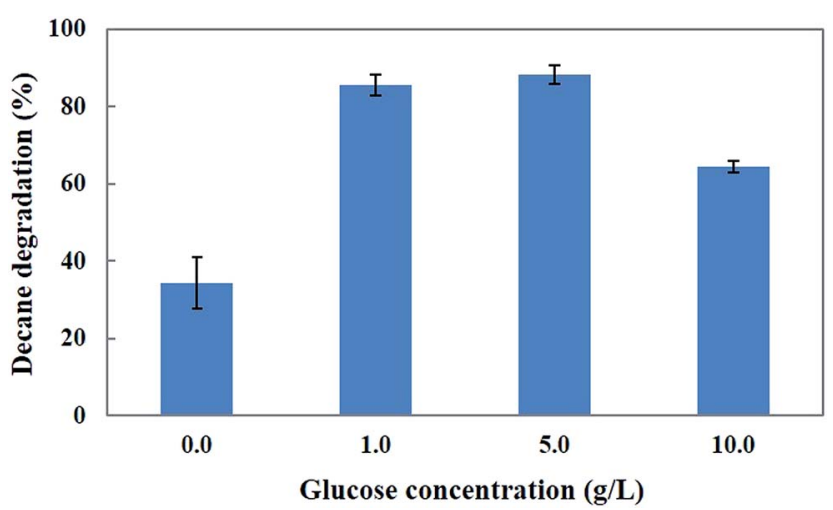

Fig. 4 Effect of glucose on decane degradation using $\mathrm{CHY}-2$. 


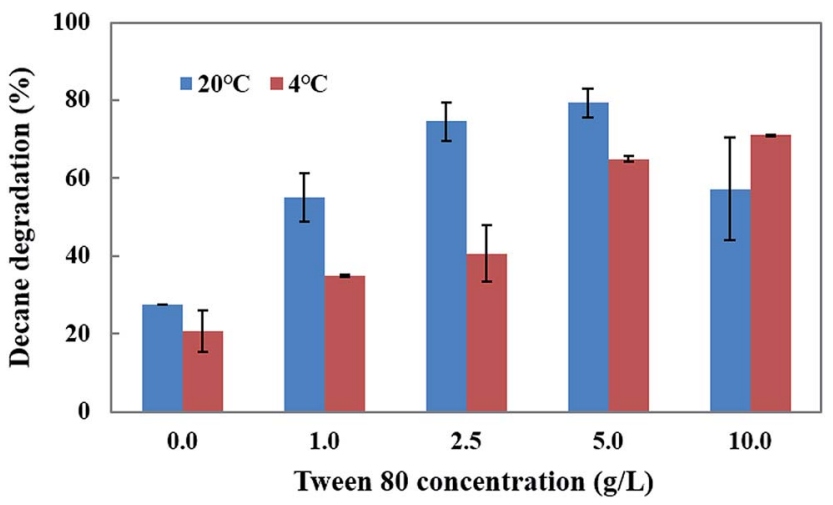

Fig. 5 Effect of Tween-80 on decane degradation using $\mathrm{CHY}-2$.

conditions ( $\mathrm{pH}$ 4.0-6.0) (Fig. 3). Decane degradation was high at pH 6.0 (81\%) followed by that at pH 8.0 (56\%) and pH 7 (40\%). The results indicate that the $\mathrm{CHY}-2$ strain is able to degrade decane under acidic conditions rather than alkaline conditions.

\section{Effect of glucose on decane degradation}

Generally, microorganisms require suitable growth conditions (e.g., carbon sources, nutrients, temperature, $\mathrm{pH}$, redox potential and oxygen content) which strongly affect their growth. The carbon source of the growth medium is an important factor for the growth and metabolism of a microorganism. Selection of an ideal and inexpensive carbon source accelerates the growth of the fungus as well as the bioremediation process. ${ }^{29}$ Our previous study $^{18}$ identified glucose as the best carbon source for the biodegradation of 4-tert-butylphenol (4-BP) by the CHY-2 strain. Thus, we selected glucose as the carbon source for decane degradation in this study (Fig. 4). The results showed that 1 and $5 \mathrm{~g} \mathrm{~L}^{-1}$ concentrations of glucose resulted in 85.3 and $88.3 \%$ decane degradation. However, $10 \mathrm{~g} \mathrm{~L}^{-1}$ of glucose resulted in a lower level of decane degradation (64.3\%) than $5 \mathrm{~g} \mathrm{~L}^{-1}$ of glucose in the medium. Based on the results, it was concluded that $5 \mathrm{~g} \mathrm{~L}^{-1}$ of glucose resulted in the highest removal of decane. The medium without glucose served as the control in this experiment. Chang et al. ${ }^{18}$ reported that the cultures promoted the degradation activity of CHY-2 at $1 \mathrm{~g} \mathrm{~L}^{-1}$ glucose concentration. Ron and Rosenberg ${ }^{30}$ reported that adding glucose as the carbon source resulted in higher rates of $n$ eicosane degradation compared to the control. Furthermore, the addition of a carbon source accelerates the biodegradation of petroleum hydrocarbon pollutants.

\section{Effect of Tween 80 on decane degradation}

Tween 80 is a water soluble synthetic compound which enhances the biodegradation and bioremediation of toxic pollutants. Thus, the influence of Tween 80 at different concentrations (1-10.0 $\left.\mathrm{g} \mathrm{L}^{-1}\right)$ and temperatures $\left(4\right.$ and $\left.20{ }^{\circ} \mathrm{C}\right)$ on decane degradation was investigated (Fig. 5). The results show that an increased concentration of Tween $80\left(1,2.5\right.$ and $\left.5 \mathrm{~g} \mathrm{~L}^{-1}\right)$ in the medium causes a gradual increase in decane degradation $(55.0 \%, 74.5 \%$, and $79.3 \%)$ at $20{ }^{\circ} \mathrm{C}$. However, a $10 \mathrm{~g} \mathrm{~L}^{-1}$ concentration of Tween 80 caused a decrease in degradation (57.2\%) compared to $5 \mathrm{~g} \mathrm{~L}^{-1}(79.3 \%)$ at $20{ }^{\circ} \mathrm{C}$.
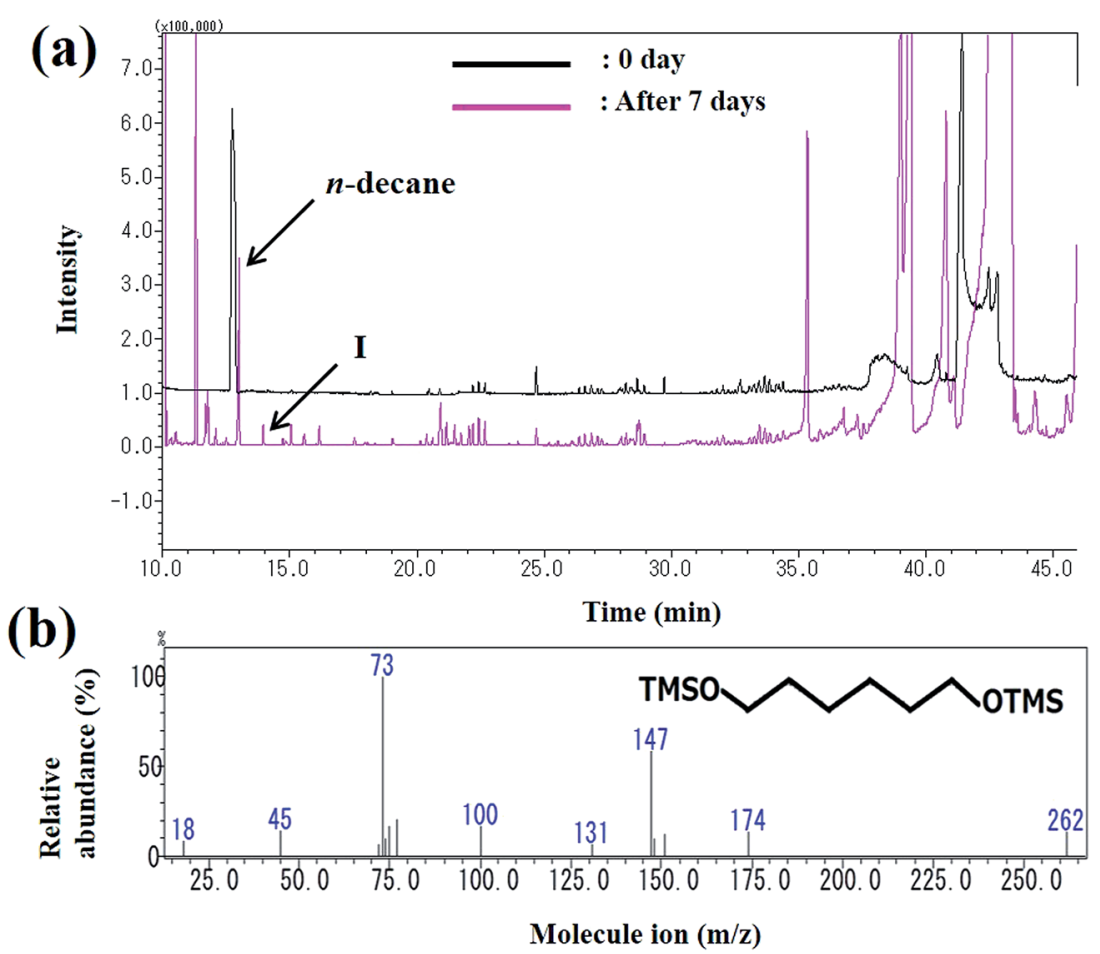

Fig. 6 (a) Gas chromatogram of the intermediates produced during decane degradation; (b) mass spectrum of the metabolite (1,6-hexanediol) identified by GC-MS. 
Table 1 Purification steps of MnP from Penicillium sp. CHY-2

\begin{tabular}{llll}
\hline & $\begin{array}{l}\text { Activity } \\
\text { Purification step }\end{array}$ & $\begin{array}{l}\text { Protein } \\
(\mathrm{mg} \mathrm{mL}\end{array}$ & $\begin{array}{l}\text { Specific activity } \\
\left(\mu \mathrm{mol} \mathrm{min} \mathrm{mg}^{-1} \mathrm{mg}^{-1} \text { protein }\right)\end{array}$ \\
\hline Crude enzyme & 1.0492 & 0.0175 & 59.95 \\
Ion-exchange & 0.2278 & 0.0009 & 253.00 \\
Gel filtration & 0.0414 & 0.0001 & 414.00
\end{tabular}

The addition of Tween 80 enhances the decane degradation activity of CHY-2 even at low temperature conditions. The increased concentrations of Tween $80\left(1,2.5,5\right.$, and $\left.10 \mathrm{~g} \mathrm{~L}^{-1}\right)$ in the medium caused gradual increases in decane degradation $(34.9 \%, 40.5 \%, 64.9 \%$ and $70.9 \%)$ at $4{ }^{\circ} \mathrm{C}$. Based on these results, it was concluded that Tween 80 may play an important role in the degradation of toxic compounds in low temperature environments. Garon et $a .^{31}$ reported that the addition of Tween 80 enhanced the biodegradation of fluorine by Doratomyces stemonitis (46-62\%) and Penicillium chrysogenum (28$61 \%)$. Wang et al. ${ }^{32}$ reported that Tween 80 acts as a stimulant for benzene[a]pyrene degradation in contaminated soil. The positive effect of Tween 80 on pyrene biodegradation by $\mathrm{PAH}$ degrading Burkholderia cepacia was observed by Chen et al. ${ }^{33}$ Budde et $a l .{ }^{34}$ reported that a Ralstonia eutropha culture with Tween 80 showed considerably higher optical densities than the control (without Tween 80), and that Tween 80 can serve as an effective carbon source for $R$. eutropha. It was established that the Tween molecules contain fatty acid groups that are cleaved by esterase, allowing them to be utilized as a carbon source by many microorganisms.

\section{Determination of decane metabolites}

The peak area of decane seen at the retention time of $13 \mathrm{~min}$ decreased as the reaction progressed and the metabolites were observed. The peak (peak I) at the retention time of 13 min was identified as 1,6-hexanediol (Fig. 6). The mass spectrum of 1,6hexanediol is shown in Fig. $6 \mathrm{~b}$. The largest molecular ion at $\mathrm{m} / \mathrm{z}$ 262 was presumed to be a decane derivative of 1,6-hexanediol. The mass spectrum corresponds to that of a previous report of decane metabolites. ${ }^{35}$

\section{Purification of MnP from Penicillium sp. CHY-2}

MnP secreted by Penicillium sp. CHY-2 was purified as described in Table 1. The crude enzyme obtained from strain CHY-2 contained 1.0492 U of MnP. The crude MnP was fractionated by ion exchange chromatography at $\mathrm{pH}$ 8.0. The fractions corresponding to $\mathrm{MnP}$ were collected and further purified by gel filtration chromatography (Fig. 7a and b). The elution pattern on the column showed 4 major peaks at $270 \mathrm{~nm}$. Similar MnP peaks were observed by Zeng et al. ${ }^{23}$ The fractions with high MnP activity were pooled, concentrated and loaded onto a HiPrep 16/60 Sephacryl S-300 (GE Healthcare Sweden) column. The molecular weight of the purified MnP was analyzed by SDS-PAGE. The purified MnP from the CHY-2 strain revealed a single band in SDS-PAGE with an estimated (a)

(b)
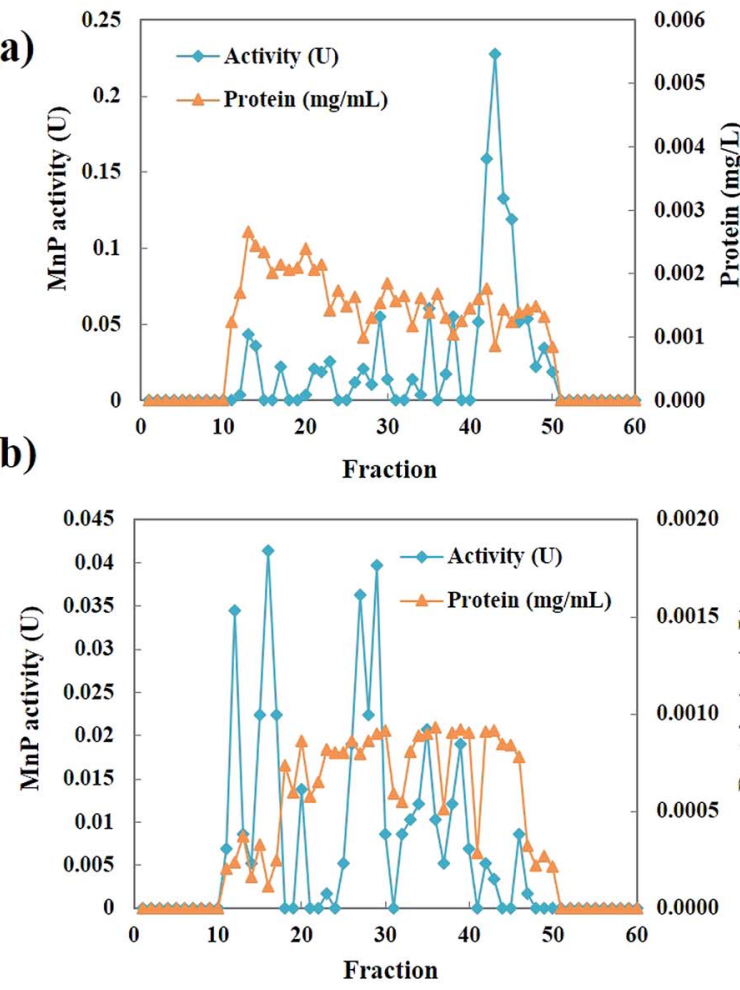

(c)

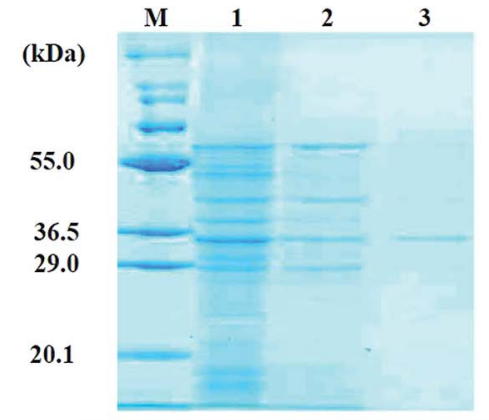

(d)

M: Protein marker;

1: Crude MnP;

2: Ion exchange purified MnP;

3: Gel filtration $\mathrm{MnP}$

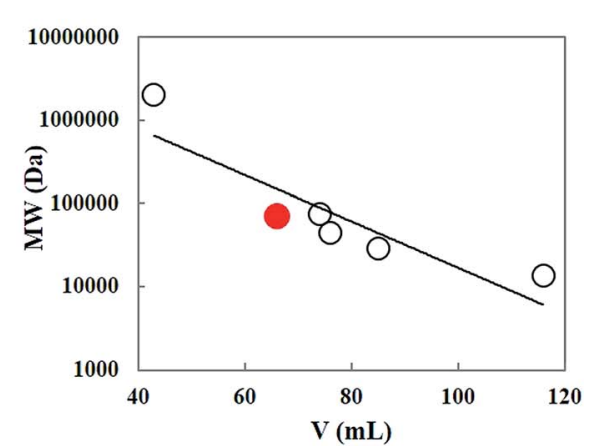

Fig. 7 Elution profile of the MnP from Penicillium sp. CHY-2. (A) Ion-exchange chromatography; (B) gel filtration chromatography; (C) SDSPAGE of purified MnP; (D) molecular mass of MnP. 

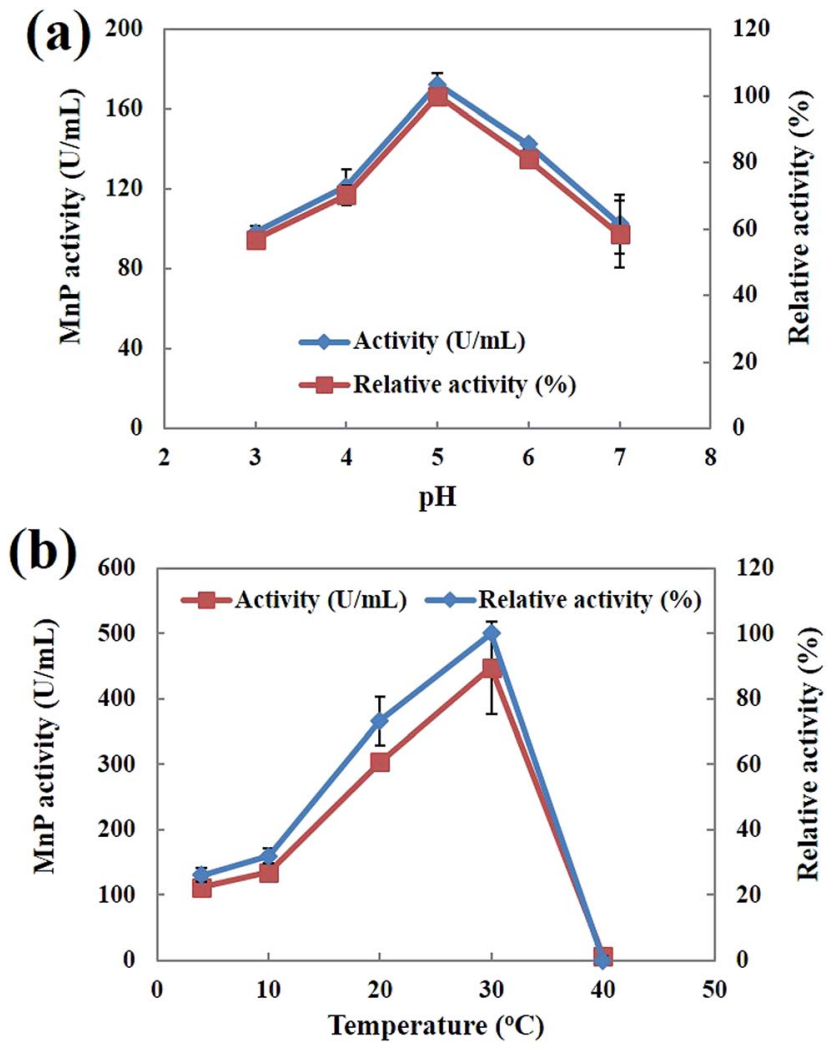

Fig. 8 (a) Effect of $\mathrm{pH}$ on MnP activity; (b) effect of temperature on $\mathrm{MnP}$ activity.

molecular mass of $36.0 \mathrm{kDa}$ (Fig. 7c). Molecular masses of fungal MnPs usually range from 32.0 to $75.0 \mathrm{kDa}^{36,37}$ Furthermore, gel filtration using a Sephacryl S-300 column was performed in order to determine the size and subunit composition of MnP. A single peak was observed for the native form of $\mathrm{MnP}$ with a relative molecular mass estimated to be $36 \mathrm{kDa}$ (Fig. 7d). This result, correlated with the observations made through SDSPAGE, indicates that the native form of $\mathrm{MnP}$ has a monomer conformation..$^{21} \mathrm{MnP}$ is a lignolytic enzyme produced by most white-rot fungi ${ }^{38}$ However, some filamentous fungal species like Penicillium also have been reported as MnP producing fungi. Urek et al. ${ }^{39}$ reported the production of MnP by $P$. chrysosporium with a molecular mass of $45 \mathrm{kDa}$.

\section{Effect of $\mathrm{pH}$ and temperature on the activity of MnP}

Both $\mathrm{pH}$ and temperature play an important role in determining the activity and stability of enzymes. ${ }^{40}$ The effect of $\mathrm{pH}$ on the activity profiles of $\mathrm{MnP}$ was investigated at $30{ }^{\circ} \mathrm{C}$ with different $\mathrm{pH}$ values (pH 3.0-7.0) in $50 \mathrm{mM}$ malonic acid (pH 2.0-5.5), and $50 \mathrm{mM}$ potassium phosphate (pH 6.0-7.0) buffers. As shown in Fig. $8 \mathrm{a}$ the optimum $\mathrm{pH}$ value was estimated to be 5.0. The $\mathrm{pH}$ value appeared to be critical for MnP activity. The maximum MnP activity is within a close range of the previously reported MnP produced by Phanerochaete chrysosporium. ${ }^{23}$ The highest MnP activity exhibited at pH 5.0 is a very important attribute that lends further support to the potential use of MnP for the degradation of hydrocarbons and PAHs. Muhammad Asgher et $a l .^{40}$ reported that
Table 2 Kinetic parameters of MnP from Penicillium sp. CHY-2

\begin{tabular}{lr}
\hline$K_{\mathrm{m}}(\mu \mathrm{M})$ & 1.31 \\
$V_{\max }\left(\mu \mathrm{M} \min ^{-1}\right)$ & 185.19 \\
$k_{\text {cat }}\left(\min ^{-1}\right)$ & 1395.06 \\
$k_{\text {cat }} / K_{\mathrm{m}}\left(\mu \mathrm{M}^{-1} \mathrm{~min}^{-1}\right)$ & 1061.03 \\
$k_{\mathrm{d}}(-)$ & 1.25 \\
\hline
\end{tabular}

increases in the $\mathrm{pH}$ caused a rapid decrease in activity, indicative of enzymatic deactivation at non-optimal $\mathrm{pH}$ values. The effect of temperature on the $\mathrm{MnP}$ activity was investigated in the temperature range of $4-40^{\circ} \mathrm{C}$. The optimum temperature of $\mathrm{MnP}$ was observed at $30^{\circ} \mathrm{C}$ (Fig. 8b). Similarly the optimum temperature for white-rot fungus Phanerochaete chrysosporium $\mathrm{MnP}$ was obtained at $30{ }^{\circ} \mathrm{C} .{ }^{23,39}$ Bilal et al. ${ }^{41}$ reported that $\mathrm{MnP}$ showed better activity at higher temperatures, which may be due to the strengthening of the protein molecule's structural rigidity when it binds to the solid support, reducing the molecular flexibility.

\section{Kinetic analysis of MnP}

The substrate specificity analysis indicated that MnP was able to oxidize the $\mathrm{Mn}^{2+}$ substrate. The kinetic constants of MnP with the $\mathrm{Mn}^{2+}$ substrate are shown in Table 2. The $K_{\mathrm{m}}$ and $V_{\max }$ values for $\mathrm{MnP}$ towards $\mathrm{Mn}^{2+}$ were $1.31 \mu \mathrm{M}$ and $185.19 \mu \mathrm{M}$ $\min ^{-1}$ respectively. The substrate specificity analysis elucidates the characteristics of toxic compound degradation.

\section{Decane degradation by MnP}

Fig. 9 shows the degradation rate of decane after treatment with $\mathrm{MnP}$ in the batch experiments. A maximum of $25.5 \%$ decane degradation was observed after $48 \mathrm{~h}$ under optimum $\mathrm{pH}(\mathrm{pH}$ 5.5) and temperature $\left(30^{\circ} \mathrm{C}\right)$ conditions. The results indicate that the MnP preparations resulted in a moderate decane biodegradation efficiency, therefore MnP has potential to be used for decane biodegradation. The potential of $\mathrm{MnP}$ in decane degradation may involve the formation of $\mathrm{MnP}-\mathrm{H}_{2} \mathrm{O}_{2}-$ $\mathrm{Mn}^{2+}$ during continuous treatment, by combining the action of the enzyme, $\mathrm{Mn}^{2+}$, an organic chelator and hydrogen peroxide, to increase hydrocarbon solubility. ${ }^{42}$

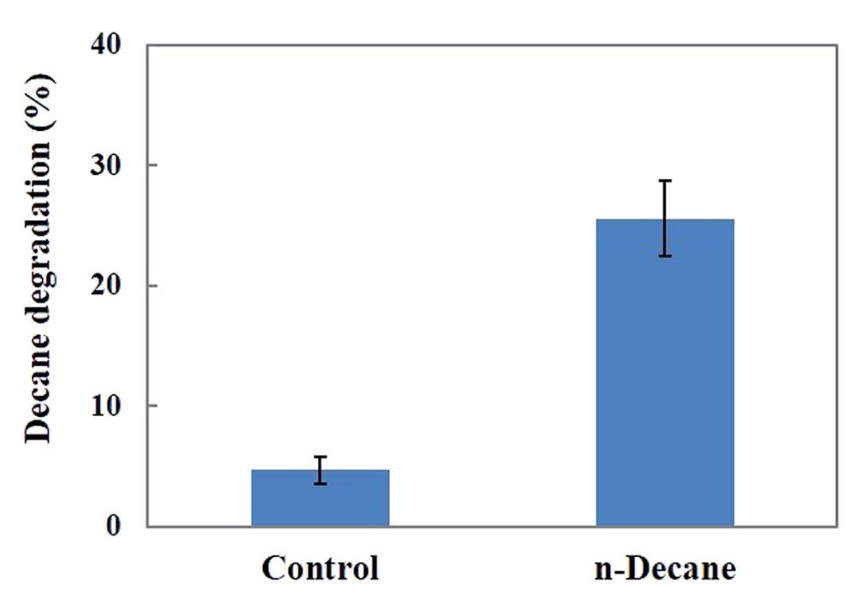

Fig. 9 Effect of MnP on decane degradation. 


\section{Conclusions}

A novel fungal strain, Penicillium sp. CHY-2, isolated from Antarctic soils, was effective for the degradation of decane at lower $\left(20^{\circ} \mathrm{C}\right)$ and medium $\left(30^{\circ} \mathrm{C}\right)$ temperatures. The degradation of decane $(49.0 \%)$ by $\mathrm{CHY}-2$ indicated its hydrocarbon degradation ability. Glucose was found to be the most suitable carbon source for the growth of CHY-2, and the addition of Tween 80 enhanced the growth and degradation ability of CHY2 towards decane. The MnP from CHY-2 was purified, and showed good activity at an optimal $\mathrm{pH}$ and temperature of 5.0 and $30{ }^{\circ} \mathrm{C}$ respectively. The results suggest that the CHY-2 strain and the MnP produced may be considered as potential candidates for the degradation of decane.

\section{Acknowledgements}

Dr M. Govarthanan gratefully acknowledges the Muroran Institute of Technology for providing Postdoctoral fellowship. This work was supported by a Grant-in-Aid for Scientific Research C (26340067) from the Japan Society for the Promotion of Science. Thanks to Dr M. V. Reddy and Dr Yuka Yajima for their helpful discussion.

\section{References}

1 S. Kuppusamy, P. Thavamani, M. Megharaj and R. Naidu, Int. Biodeterior. Biodegrad., 2016, 108, 149-157.

2 S. J. Robertson, W. B. McGill, H. B. Massicotte and P. M. Rutherford, Biol. Res., 2007, 82, 213-240.

3 C. O. Nwoko, Journal of Geoscience and Environment Protection, 2014, 2, 9-14.

4 M. Rajtor and Z. Piotrowska-Seget, Chemosphere, 2016, 162, 105-116.

5 A. G. Khan, C. Kuek, T. M. Chaudhry, C. S. Khoo and W. J. Hayes, Chemosphere, 2000, 41, 197-207.

6 S. Gan, E. V. Lau and H. K. Ng, J. Hazard. Mater., 2009, 172, 532-549.

7 M. Hassanshahian, G. Emtiazi and S. Cappello, Mar. Pollut. Bull., 2012, 64, 7-12.

8 K. Kubota, D. Koma, Y. Matsumiya, S. Y. Chung and M. Kubo, Biodegradation, 2008, 19, 749-757.

9 X. Song, Y. Xu, G. Li, Y. Zhang, T. Huang and Z. Hu, Mar. Pollut. Bull., 2011, 62, 2122-2128.

10 D. Hou, X. Shen, Q. Luo, Y. He, Q. Wang and Q. Liu, Mar. Pollut. Bull., 2012, 67, 146-151.

11 V. Patel, J. Patel and D. Madamwar, Mar. Pollut. Bull., 2013, 74, 199-207.

12 H. Harms, D. Schlosser and L. Y. Wick, Nat. Rev. Microbiol., 2011, 9, 177-192.

13 K. A. Hughes and P. Bridge, Tolerance of Antarctic soil fungi to hydrocarbons and their potential role in soil bioremediation, in Polar Microbiology: The Ecology, Biodiversity and Bioremediation Potential of Microorganisms in Extremely Cold Environments, Taylor and Francis, Boca Raton, FL, 2010, pp. 277-300.
14 K. Steffen, A. Hatakka and M. Hofrichter, Appl. Microbiol. Biotechnol., 2002, 60, 212-217.

15 P. Baborova, M. Moder, P. Baldrian, K. Cajthamlova and T. Cajthaml, Res. Microbiol., 2006, 157, 248-253.

16 G. Eibes, T. Cajthaml, M. T. Moreira, G. Feijoo and J. M. Lema, Chemosphere, 2006, 64, 408-414.

17 E. Kerry, Polar Biol., 1990, 10, 293-299.

18 Y. C. Chang, S. Fuzisawa, M. V. Reddy, H. Kobayashi, E. Yoshida, Y. Yajima, T. Hoshino and D. Choi, Clean: Soil, Air, Water, 2016, 44, 1-9.

$19 \mathrm{H}$. Wariishi, L. Akileswaranand and M. H. Gold, Biochemistry, 1988, 27, 5365-5370.

20 M. B. Martel, R. Letoublon and M. Fevre, Curr. Microbiol., 1996, 33, 243-248.

21 J. A. Tamayo-Ramos, W. J. H. van Berkel and L. H. de Graaff, Microb. Cell Fact., 2012, 11, 165.

22 U. K. Laemmli, Nature, 1970, 227, 680-685.

23 G. M. Zeng, M. H. Zhao, D. L. Huang, C. Lai, C. Huang, Z. Wei, P. Xu, N. J. Li, C. Zhang, F. L. Li and M. Cheng, Int. Biodeterior. Biodegrad., 2013, 85, 166-172.

24 J. E. Dowd and D. S. Riggs, J. Biol. Chem., 1965, 240, 863-869. 25 A. L. Leitao, Int. J. Environ. Res. Public Health, 2009, 6, 1393-1417. 26 H. Singh, Mycoremediation: Fungal Bioremediation, WileyInterscience, New York, 2006.

27 S. Boonchan, M. L. Britzand and G. A. Stanley, Appl. Environ. Microbiol., 2000, 66, 1007-1019.

28 L. Launen, L. J. Pintoand and M. M. Moore, Appl. Microbiol. Biotechnol., 1999, 51, 510-515.

29 M. V. Reddy and S. V. Mohan, Bioresour. Technol., 2012, 114, 573-582.

30 E. Z. Ron and E. Rosenberg, Curr. Opin. Biotechnol., 2014, 27, 191-194.

31 D. Garon, S. Krivobok, D. Wouessidjewe and F. SeigleMurandi, Chemosphere, 2002, 47, 303-309.

32 C. Wang, H. Liu, J. Li and H. Sun, Environ. Sci. Pollut. Res., 2014, 21, 10614-10625.

33 K. Chen, Q. Zhu, Y. Qian, Y. Song, J. Yao and M. M. F. Choi, Ecotoxicol. Environ. Saf., 2013, 98, 361-367.

34 C. F. Budde, S. L. Riedel, F. Hubner, R. Risch, M. K. Popovic, C. K. Rha and A. J. Sinskey, Appl. Microbiol. Biotechnol., 2011, 89, 1611-1619.

35 K. Syed, A. Porollo, Y. W. Lam, P. E. Grimmett and J. S. Yadav, Appl. Environ. Microbiol., 2013, 79, 2692-2702.

36 C. G. Boer, L. Obici, C. G. M. de Souza and R. M. Peralta, Bioresour. Technol., 2004, 94, 107-112.

37 P. L. de Oliveira, M. C. T. Duarte, A. N. Ponezi and L. R. Durrant, Braz. J. Microbiol., 2009, 40, 818-826.

38 F. Peláez, M. J. Martinez and A. T. Martinez, Mycol. Res., 1995, 99, 37-42.

39 R. O. Urek and N. K. Pazarlioglu, Process Biochem., 2004, 39, 2061-2068.

40 M. Asgher, M. Ramzan and M. Bilal, Chin. J. Catal., 2016, 37, 561-570.

41 M. Bilal, M. Iqbal, H. Hu and X. Zhang, Biochem. Eng. J., 2016, 109, 153-161.

42 G. Eibes, T. Lú Chau, G. Feijoo, M. T. Moreira and J. M. Lema, Enzyme Microb. Technol., 2005, 37, 365-372. 